\title{
O modelo IS-LM-EE para economias abertas e distinções dos efeitos para as economias nacionais ${ }^{1}$
}

\author{
Gustavo Inácio de Moraes ${ }^{2}$ \\ Maurício Aguiar Serra ${ }^{3}$
}

\begin{abstract}
Resumo
O meio ambiente tem-se tornado uma crescente fonte de preocupações e o debate acerca das incompatibilidades entre crescimento econômico e preservação ambiental está muito distante de findar. Dentro desse contexto, diversas propostas de incorporação das restrições ambientais na macroeconomia foram feitas, sendo o modelo IS-LM-EE um dos mais interessantes. Sua grande limitação, entretanto, provém do fato de ele ter sido construído para economias fechadas. Quando utilizado para economias abertas, os resultados são completamente distintos na medida em que os países em desenvolvimento e desenvolvidos estão em situação oposta à exploração dos recursos naturais. Nesse sentido, há uma acentuada diferença entre eles quanto à adoção de políticas e às respostas aos choques econômicos, diferença essa ampliada quando as restrições ambientais são levadas em consideração, principalmente, no caso dos choques exógenos derivados do comércio internacional.
\end{abstract}

Palavras-chave: Meio ambiente; Modelo IS/LM/EE; Países em desenvolvimento; Comércio internacional; Macroeconomia.

\section{Abstract}

The IS-LM-EE model for open economies and particular effects on the national economies

The environment is a growing source of concern and the debate on the incompatibilities between economic growth and environmental conservation is far from over. In this context, a number of proposals for introducing environmental restrictions into macroeconomics have been made, the ISLM-EE model being the most interesting one. However, this model has a serious limitation insofar as it was built for closed economies. When this model is used for open economies, the outcome differs greatly, given that developing and developed economies show major differences with respect to the exploitation of natural resources. There are considerable differences between them with respect to policies to be adopted as well as solutions required to combat economic shocks. These differences intensify when environmental restrictions are taken into consideration, principally in the case of exogenous shocks resulting from international trade.

Key words: Environment; IS/LM/EE model; Developing countries; International trade; Macroeconomics.

JEL E60, F18, Q56.

(1) Trabalho recebido em outubro de 2007 e aprovado em novembro de 2009.

(2) Professor do Programa de Pós-graduação em Economia (PPGE) da Pontifícia Universidade Católica do Rio Grande do Sul (PUCRS), Porto Alegre, RS, Brasil. E-mail: gustavo.moraes@pucrs.br.

(3) Professor Doutor do Instituto de Economia da Universidade Estadual de Campinas (IE/Unicamp), Campinas, SP, Brasil. E-mail: mserra@eco.unicamp.br.

Economia e Sociedade, Campinas, v. 20, n. 1 (41), p. 53-78, abr. 2011. 


\section{Introdução}

A produção de bens e serviços para necessidades humanas e sua alocação junto aos agentes têm-se constituído em preocupação dos economistas desde o surgimento da economia moderna. Nessa ótica, o estudo da economia irá restringir-se à determinação de equilíbrios e efeitos da adoção de certas políticas econômicas sobre os mercados. Sempre, entretanto, foi uma questão de difícil incorporação considerar as externalidades oriundas da produção dos bens e serviços, sobretudo quando os efeitos da prosperidade eram evidentes para todos, particularmente, durante a Era do Ouro do Capitalismo no período pós-guerra até meados dos anos 70. Novos desafios e incorporações teóricas foram propostas nos anos posteriores e, notadamente, o debate acerca da incorporação das dimensões ambientais ampliou-se.

As discussões acerca do esgotamento dos recursos naturais e seu melhor aproveitamento intensificaram-se paulatinamente, ao longo dos anos e culminaram com o relatório Brundtland, publicado em 1987 sob os auspícios das Nações Unidas. Também conhecido como Nosso Futuro Comum, o relatório foi o responsável não só pela introdução, como também pela disseminação do conceito de desenvolvimento sustentável, o qual está centrado em três linhas básicas: crescimento econômico, equidade social e equilíbrio ecológico (CMMAD, 1991). A sustentabilidade, de um ponto de vista econômico, necessita de duas condições para ser viabilizada: a ampliação (ou, no mínimo, a conservação) da qualidade de vida em longo prazo e a manutenção do estoque de capital que inclui os recursos naturais em dado horizonte de tempo. $\mathrm{Na}$ realidade, a conciliação entre desenvolvimento econômico e preservação dos recursos naturais, objeto central da noção de sustentabilidade, continua sendo um objetivo a ser alcançado, apesar dos esforços realizados no âmbito de políticas públicas desde a publicação do Nosso Futuro Comum.

As contribuições e sugestões da teoria econômica para a promoção da sustentabilidade ambiental têm-se concentrado majoritariamente, na área microeconômica (a determinação do uso ótimo da extração de recursos naturais, as metodologias de valoração, a internalização dos custos ambientais pelos agentes econômicos etc.), sendo a macroeconomia curiosamente relegada a segundo plano. Notáveis exceções podem ser atribuídas aos trabalhos de Leontief (1970) e Daly (1991), sendo que o último fez um verdadeiro apelo ao surgimento de uma macroeconomia ambiental em função da relação existente entre macroeconomia e meio ambiente, uma vez que esta sempre foi negligenciada pela literatura econômica (Lawn, 2003). Desde então, a literatura a respeito de uma contabilidade nacional com aspectos ambientais e indicadores de desenvolvimento sustentável cresceu significativamente. Essas realizações, contudo, eram no campo prático, posto que as contribuições teóricas inexistiam. 
Do ponto de vista teórico, uma primeira resposta à provocação de Daly(1991) veio com o artigo de Heyes (2000), que inseriu a restrição ambiental sob a forma de uma nova curva, denominada EE, no tradicional modelo IS-LM. Essa alteração resultou no modelo IS-LM-EE cujo "equilíbrio ambiental" residia na curva EE. O novo modelo foi ampliado por Lawn (2003) que introduziu o papel do progresso tecnológico e os benefícios líquidos sustentáveis da atividade econômica com o propósito de verificar as implicações nas políticas monetária e fiscal. O modelo, no entanto, utilizado por Lawn é incompleto na medida em que ele está restrito a uma economia sem transações com o exterior. De fato, o comércio internacional exerce diferentes impactos nos países, pois os que estão em desenvolvimento têm, em geral, um comércio exterior baseado em produtos primários e as regulamentações para a utilização de seus recursos naturais são frágeis, muitas vezes, ineficazes. Por outro lado, os países desenvolvidos vivenciam outra realidade, ou seja, sua pauta de exportação, em quase a totalidade, compõe-se de bens manufaturados. Há uma regulamentação mais eficiente do uso dos recursos naturais, além do mais, uma significativa proteção em comparação aos países em desenvolvimento dos recursos naturais ainda disponíveis.

O objetivo do presente artigo é ampliar o modelo IS-LM-EE, originalmente, concebido por Heyes (2000), para a economia aberta e, em paralelo, demonstrar a possibilidade de diferenças qualitativas de resultados para países desenvolvidos e em desenvolvimento. Para tanto, ele está estruturado em cinco seções além dessa introdução. Na primeira seção, o modelo IS-LM-EE para uma economia fechada é apresentado, tendo por base os trabalhos de Heyes (2000) e Lawn (2003). Na segunda seção, o modelo IS-LM-EE é desenvolvido para economias abertas. A terceira seção procura assinalar efeitos distintos nas economias nacionais, demonstrando que o padrão ambiental do comércio internacional tem efeitos distintos entre os países desenvolvidos e em desenvolvimento, sendo os comentários finais tecidos na quarta e na última seção.

\section{O Modelo IS-LM-EE}

Em 1937, John R. Hicks publicou o artigo "Mr. Keynes and the classics: a suggested interpretation" que teve um significativo impacto na literatura econômica na medida em que sua representação proposta não só serviu como instrumento amplamente utilizado na análise de políticas econômicas, como também foi adotada por grande parte dos atuais livros-texto de macroeconomia (Andrade; Magalhães, 2004). De fato, a maneira simplificada com que Hicks resumiu as principais concepções de Keynes contidas em seu livro A Teoria Geral do Emprego, do Juro e da Moeda, publicado em 1936, foi fundamental para que o modelo IS-LM viesse a tornar-se bastante popular, sendo seu diagrama utilizado 
de maneira ampla, na análise de políticas macroeconômicas, principalmente, no que tange a seus impactos sobre o nível de renda.

Segundo Krugman (1998), o modelo IS-LM é, na verdade, um modelo de equilíbrio geral. Apesar da necessidade de encontrar-se um equilíbrio temporário e todas as controvérsias que possam advir desse fato, trata-se de um modelo usual e sua simplicidade é suficiente para raciocinar-se sobre os impactos na economia. Krugman atribui à praticidade do modelo sua sobrevivência como instrumento de raciocínio e análise.

A eclosão da Segunda Guerra Mundial foi um fator decisivo na disseminação das ideias keynesianas que passaram a ter, na concepção de Hirschman (1989), uma influência preponderante a partir do momento em que foram adotadas e implementadas pelos Estados Unidos, a grande potência vencedora da II Guerra, em vários programas de ajuda econômica no período do pós- guerra. Esse autor destaca três importantes efeitos das ideias keynesianas: a) o surgimento de um consenso sobre política econômica no período do pós- guerra; b) a infusão do espírito público e esperança de que os males sociais pudessem ser superados; c) a inspiração de várias novas ideias econômicas, sendo uma delas a da economia do desenvolvimento, cujo foco estava centrado nos países subdesenvolvidos. De fato, o arcabouço teórico keynesiano durante quase trinta anos, especificamente em meados da década de 1940 a 1970, foi o responsável por uma relativa estabilidade política, também, por um contínuo e expressivo progresso econômico no mundo, período caracterizado como a Era de Ouro do Capitalismo.

O declínio do keynesianismo ocorre justamente com o primeiro choque do petróleo, em 1973 e o concomitante surgimento da estagflação (Hirschman, 1989). Nesse sentido, o predomínio teórico keynesiano veio a ser, veementemente, contestado pelas doutrinas monetarista e supply-side, que passaram a responsabilizar as políticas econômicas keynesianas e os compromissos fiscais assumidos pelo welfare state como os grandes vilões da crise mundial vivenciada a partir de 1973 (Fiori, 1997). É interessante notar que, exatamente nessa época, se inicia uma preocupação mais acentuada com o meio ambiente na medida em que se tornam notórios os impactos ambientais adversos causados pelo crescimento econômico contínuo e tecnologia à disposição do homem para a realização de suas necessidades materiais.

As políticas econômicas keynesianas foram, na realidade, implementadas em larga escala desde o pós-II Guerra até a primeira crise do petróleo ocorrida em 1973, tendo a intervenção do Estado na economia como pressuposto básico. Além disso, a política fiscal e a monetária eram consideradas instrumentos eficazes e suficientes para o gerenciamento macroeconômico. O ponto central, no entanto, é 
que as questões ambientais, independentemente da concepção das principais correntes de pensamento econômico, têm permanecido à margem da teoria macroeconômica, ou seja, os modelos macroeconômicos ainda não incorporaram as preocupações com o meio ambiente. Isso não significa, em absoluto, que os aspectos ambientais nunca tenham feito parte de discussões sobre assuntos macroeconômicos, sendo um bom exemplo à vasta literatura divulgada a respeito da contabilidade ambiental (Atkinson et. al., 1997; El Serafy, 1999).

Sendo assim, é plenamente justificável que qualquer tentativa de aperfeiçoamento da análise econômica tenha, na metodologia IS-LM, um importante instrumento como no caso da proposta de Heyes (2000). Preocupado com a ausência de limites ambientais na macroeconômica, Heyes propôs um novo esquema a partir da inclusão da variável ambiental na análise IS-LM. É interessante notar que, igual à metodologia original, o autor não recorreu à base microeconômica. Tal fato ganha considerável importância, uma vez que a microeconomia tem importantes insights a respeito do tratamento dos recursos naturais, sendo excelentes exemplos os métodos de valoração econômica e a análise das externalidades.

A proposta de Heyes (2000) foi a de incorporar ao esquema IS-LM mais uma dimensão de análise, denominada "equilíbrio ambiental" (EE). Para construir a curva EE, o referido autor serviu-se de uma medida de eficiência da produção avaliada em termos de usos energéticos, proposta por Ayres (1978). O conceito, representado pela letra $\mathrm{E}$, é resultado da razão entre a energia total usada no processo produtivo e a total disponível nos produtos utilizados em tal produção. Como ilustração, com a utilização de técnicas mais poluidoras, E aproxima-se de zero e, com a difusão de técnicas mais limpas, aproxima-se de 1, jamais alcançando seus valores extremos. De acordo com Lawn (2003), isso ocorre porque a produtividade ambiental de uma atividade econômica ou de uma tecnologia, por maior que seja, estaria condicionada pela primeira e a segunda lei da termodinâmica.

No modelo proposto, a curva EE seria influenciada por três parâmetros: taxa real de juros de longo prazo $(\mathrm{R})$; institucional que mede custos da poluição e o nível de depleção dos recursos $(\beta)$ e o tecnológico $(\gamma)$. Os dois últimos parâmetros variam entre zero e um e estão relacionados, positivamente, ao parâmetro $\mathrm{E}$, enquanto a taxa real de juros de longo prazo está relacionada, negativamente, com o parâmetro ambiental. O parâmetro tecnológico mede o quanto a função de produção da economia estudada poupa recursos e reduz emissões e resíduos. Com efeito, a adoção de técnicas que sejam mais econômicas no uso de recursos naturais e disseminem menos emissões e resíduos, a curva EE irá para uma posição menos restritiva no sistema econômico. Por sua vez, o 
parâmetro institucional tem a função de adicionar ao modelo efeitos spillover na depleção dos recursos e custos de poluição toleráveis por usuário.

Dessa forma, o esquema originalmente apresentado em Ayres (1978) e aproveitado na proposta, pode ser assim representado:

$$
\mathrm{E}=\frac{\mathrm{Y}}{\mathrm{T}}
$$

O Y indica a energia disponível incorporada na produção de bens e serviços e T representa o parâmetro da razão entre a quantidade de recursos que ingressam no sistema com as deduzidas perdas. Elas ocorrem nessa incorporação, ou seja, é o throughput total de energia material. De outra forma, portanto, $\mathrm{T}$ pode ser entendido como a razão de $\mathrm{Y}$ por $\mathrm{E}(\mathrm{R}, \beta, \gamma)$. Desse modo, para que o capital natural possua capacidade de regeneração:

$$
-\left(\frac{\mathrm{dN}}{\mathrm{dt}}\right)=0=\mathrm{T}-\mathrm{s} . \mathrm{N} \quad(1) ;^{4},
$$

em que " $\mathrm{N}$ " representa o estoque físico de capital natural, " $\mathrm{t}$ " representa o tempo, "T" o throughput total de energia e, finalmente, "s" representa a taxa de regeneração do capital natural. Desse modo, a equação (1) representa os pontos em que a curva EE encontra-se em equilíbrio, o que leva a:

$$
-\left(\frac{\mathrm{dN}}{\mathrm{dt}}\right)=\left(\frac{\mathrm{Y}}{\mathrm{E}}\right)-\mathrm{s} \cdot \mathrm{N}=0 \quad(2) ;^{5}
$$

Logo, quando $(\mathrm{dN} / \mathrm{dt})=0,(\mathrm{dr} / \mathrm{dy})=\left(\mathrm{E} / \mathrm{Y} . \partial_{\mathrm{R}}\right)$, assim como $\partial_{\mathrm{R}}<0$, a curva EE terá inclinação negativa no plano (R, Y) (Lawn, 2003, p. 36).

Ambos os autores consideram que o estoque de capital natural permanece ileso à medida que a apropriação da entropia pelo sistema econômico respeite a capacidade de regeneração natural. Os deslocamentos para a direita da curva EE seriam resultados de incrementos em $\beta$ e $\gamma$ até o limite de 1, cujos parâmetros podem alcançar, relacionando-se, portanto, positivamente ao parâmetro.

O modelo IS-LM tradicional tem limitações evidentes para a economia como assinala Romer (1996), por exemplo, até destacar o fato de não existirem bases microeconômicas, o que impede análises de bem-estar. Tal limitação permanece quando se aplica a metodologia IS-LM-EE. É interessante chamar a atenção para o fato de considerar-se a economia de modo agregado, o que mascara efeitos setoriais. Outra limitação é a própria generalização entre países em desenvolvimento e países desenvolvidos, objeto de consideração em seção

(4) Equação (8) em Lawn (2003).

(5) Equação (9) em Lawn (2003). 
posterior. Mais importante, frente a duas alternativas metodológicas (uma, quantificando de modo mais preciso as ligações entre meio ambiente e atividade econômica e a outra, estabelecendo limites à economia) é que o modelo atua mais orientado para apenas uma delas, ou seja, a metodologia IS-LM-EE estaria bem caracterizada com a segunda abordagem citada, estabelecendo limites teóricos, pois a construção de relações entre efeitos da atividade macroeconômica e impactos ambientais ainda não está totalmente estruturada. ${ }^{6}$

Além do posicionamento quanto à possibilidade do capital econômico ser substituto do capital natural, as conclusões de Lawn (2003) e Heyes (2000), a partir do mesmo modelo, diferem. De acordo com o primeiro autor, as soluções de mercado para o equilíbrio ambiental ser atendido inexistem, uma vez que os mercados sinalizam, por meio dos preços, escassez relativa entre mercadorias, condições de oferta e demanda particulares, incapazes de registrar considerações de absoluto declínio nas condições de oferta, dados pela apropriação de entropia. Assim, aparece a distinção entre as posições dos dois autores.

Para Lawn (2003), duas orientações de política econômica podem fazer com que o sistema satisfaça ao equilíbrio ambiental. A primeira forma de atuação adequaria o fluxo de recursos à capacidade de regeneração natural, enquanto a segunda intervenção seria dirigida a garantir a eficiência na alocação de recursos. Uma manifestação possível dessas políticas, segundo o autor, seria a concepção de um mercado de permissão de emissões ou créditos de poluição, coordenado pelo governo, com o limite ambiental determinando o tamanho do mercado.

No caso da abordagem proposta por Heyes (2000), o equilíbrio ambiental poderia ser observado via adoção de políticas monetárias ou fiscais que atuariam sobre as variáveis econômicas e proporcionariam os deslocamentos suficientes no sistema IS-LM-EE, garantindo o equilíbrio. Lawn (2003), manifestando suas reservas, considera pouco provável que o formulador de políticas consiga determinar o efeito de tais políticas sobre a curva EE.

De outra parte, o esquema de Lawn (2003) é apenas ilustrado com situações de mercado, como a implantação de um mercado de emissões, por exemplo. ${ }^{7}$ Ambos os autores, no entanto, discordam relativamente no tocante à maneira como capital natural e capital econômico relacionam-se. Ao contrário de Heyes (2000), Lawn (2003) considera que liberdade de escolha de técnicas não garante capital natural e capital econômico serem substitutos. Deste modo, Lawn

(6) No nível microeconômico, como dito na introdução, algumas relações estão sendo estabelecidas, aplicando-se estimações de função de produção e valoração econômica entre outras. Ainda assim, uma consolidação e validação, maior dessas técnicas e sua posterior ligação com o nível macroeconômico ainda está por ser feita.

(7) É oportuno, nesse momento, recordar o alerta de Fullerton e Stavins (1998) de que soluções de mercado não são unânimes entre economistas. 
(2003) está manifestando sua posição favorável ao conceito de sustentabilidade forte. ${ }^{8}$ Posições como essa geram maiores restrições na estimação da curva EE, ao contrário do caso em que há sustentabilidade fraca. Parece, entretanto, ser mais correto considerar a sustentabilidade fraca, uma vez que o equilíbrio ambiental apoia-se no trhroughput de energia, abrindo espaço ao aperfeiçoamento das técnicas produtivas e, no limite, substituindo o capital natural.

Nesse particular, vale notar Ollikainen (1997) que contrapôs as interpretações de desenvolvimento sustentável comparando a sustentabilidade fraca com a forte. Quando o objetivo é o alcance de uma sustentabilidade forte, há dominância daquilo que se denominou ética biocêntrica, ao contrário da antropocêntrica, predominante na visão da sustentabilidade fraca. Huesemann (2003) adota a posição de muitos ecologistas industriais, acreditando que somente avanços industriais rumo à sustentabilidade não serão suficientes enquanto o crescimento econômico e o populacional forem mantidos. ${ }^{9}$

No caso, por exemplo, de uma expansão fiscal, Heyes (2000) observa um efeito amplificado de aumento da taxa real de juros de longo prazo em relação à posição tradicional keynesiana. O produto, por sua vez, sofre uma queda para que possa ajustar-se à restrição determinada pela curva EE, ao contrário do resultado padrão da IS-LM tradicional em situação keynesiana básica. Já, a análise de Lawn (2003) prevê, inicialmente, os mesmos efeitos, mas, após serem consumados os efeitos de Heyes, o dinamismo das ações dos agentes poderá levar ou não o produto a aumentar, já que deslocará ou não, positivamente, a restrição ambiental.

No caso de uma expansão monetária, Heyes (2000) percebe queda na taxa de juros real de longo prazo, enquanto há aumento do produto. Esses efeitos, todavia, seriam de menor intensidade do produto e maior intensidade da taxa de juros do que no caso keynesiano básico. Para Lawn (2003), o produto poderia ou não crescer em intensidade maior do que no caso do modelo keynesiano básico. Da mesma forma, devido à possibilidade da restrição ambiental ser vencida, a taxa real de juros de longo prazo poderia ser menor do que no caso keynesiano básico. O Quadro 1, na sequência, mostra uma síntese dos casos.

(8) No original, Lawn (2003, p. 35-36): "Unlike Heyes, I do not believe that the freedom to choose among the range of available techniques amounts to an assumption that natural and human-made capital are substitutes. (...). Yet, since Heyes's construction of the EE curve is based on the need to keep natural capital intact his model forbids what the substitutability condition supposedly permits."

(9) Em suas palavras: "... a society with strong biocentric values would choose a much smaller maximum matter-energy throughput than a society with a deep-seated anthropocentric bias" (Huesemann, 2003, p. 32). 
O modelo IS-LM-EE para economias abertas e distinções dos efeitos para as economias nacionais

Quadro 1

Resumo dos Efeitos da Metodologia IS-LM (Keynesiano Básico)

e IS-LM-EE (Heyes (2000) e Lawn (2003).

\begin{tabular}{|c|c|c|c|c|c|c|}
\hline \multirow{2}{*}{$\begin{array}{c}\text { Equilíbrio } \\
\text { Geral } \\
\text { (Efeitos sobre) }\end{array}$} & $\begin{array}{c}|c| \\
\text { Keynesiano } \\
\text { Básico }\end{array}$ & $\begin{array}{c}\text { Heyes } \\
(2000)\end{array}$ & $\begin{array}{c}\text { Lawn } \\
(2003)\end{array}$ & $\begin{array}{c}\text { Keynesiano } \\
\text { Básico }\end{array}$ & $\begin{array}{c}\text { Heyes } \\
(2000)\end{array}$ & $\begin{array}{c}\text { Lawn } \\
(2003)\end{array}$ \\
\hline Produção & + & $+(<)$ & $?(?)$ & + & $-(>)$ & $?(?)$ \\
\hline Taxa de Juros & - & $-(>)$ & $-(?)$ & + & $+(>)$ & $+(?)$ \\
\hline
\end{tabular}

Fonte: Elaboração Própria a partir de Sachs; Larrain (1995); Heyes (2000) e Lawn (2003).

Nota: os sinais entre parênteses sinalizam a intensidade do efeito em relação à posição keynesiana básica.

Além do interesse teórico, o modelo IS-LM-EE permitiria uma análise de política econômica que contemplaria a dimensão ambiental. Harris (2001), por sua vez, é cético quanto à possibilidade de um esquema simples, como o apresentado, abarcar toda a complexidade envolvida nas definições de limites ambientais. Todo o modelo, entretanto, IS-LM, como salienta o próprio Harris, possui esse problema não apenas em relação a variáveis ambientais, mas também a outras variáveis macroeconômicas relevantes.

\section{IS-LM-EE: uma aplicação para economias abertas}

Levando-se em conta os efeitos diferenciados do comércio internacional sobre países em desenvolvimento e desenvolvidos, é possível avaliar, por meio da metodologia IS-LM-EE, os impactos ambientais sobre uma economia aberta. Mesmo nessa abordagem, é preciso considerar alguns aspectos para realizar-se o exercício: 1) os efeitos econômicos quando a economia possui câmbio fixo e mobilidade perfeita de capitais; 2) os efeitos quando a economia tem câmbio flexível, mas ainda preserva a mobilidade perfeita de capitais; e 3) o comportamento sobre controle de capitais. Tais aspectos são ocorrências extremas e entre eles há inúmeras combinações lineares para sistemas cambiais. A experiência prática demonstra que as nações têm adotado, em geral, combinações intermédias de casos extremos, inclusive naquilo que diz respeito ao controle de capitais, com adoção de restrições temporárias. Embora essa ressalva seja importante para efeitos didáticos, apenas casos extremos serão alvos da atenção do presente trabalho.

A base teórica que serviu de inspiração para ampliar os resultados do modelo IS-LM é o consagrado modelo Mundell-Fleming. Nesse modelo, os fluxos de comércio respondem mais lentamente às variações nas condições econômicas básicas em relação ao movimento de capitais (Sachs; Larrain, 1995). Ao contrário da formulação de Heyes (2000) e Lawn (2003), quando a curva EE dependia de 
fatores como arranjos institucionais e tecnologias disponíveis para uso, sendo apenas a taxa real de juros de longo prazo dada endogenamente, a curva EE em uma economia aberta sofrerá os efeitos do comportamento do câmbio, coeteris paribus. Como será verificado na terceira seção, um incremento das exportações, por meio da desvalorização da moeda, nos países em desenvolvimento tende a expandir a fronteira agrícola e ampliar as exportações industriais. ${ }^{10}$

Torna-se importante salientar que o capital natural $\mathrm{N}$ e a taxa de regeneração $s$ são formados por uma heterogeneidade de componentes, o que faz de ambos indicadores agregados (Lawn, 2003, p. 36). Nesse sentido, os efeitos positivos da economia internacional sobre a economia nacional tenderiam a intensificar aquelas atividades que se valem dos recursos naturais, de um modo menos produtivo, coeteris paribus, modificando os valores de $\mathrm{T}$, s e $\mathrm{N}$, definidos na equação (2). Desse modo, quando havia uma economia fechada, era possível ignorar tal efeito, mas em uma economia aberta, esse efeito mascarado na agregação é importante na medida em que define a propensão da pauta produtiva em utilizar mais (menos) recursos naturais em função dos incentivos (esmorecimento) da economia internacional, ou seja, a conformação do aproveitamento do capital natural e taxa de regeneração modifica-se, ocasionando os deslocamentos da curva EE.

De todo modo, qualquer que seja o "enforcement" institucional, a curva EE, sob uma desvalorização cambial, teria um deslocamento à esquerda, mostrando a ampliação dos limites físicos do sistema. Na Figura 1, é demonstrado o efeito sob desvalorização do câmbio real e a Figura 2 mostra o efeito sob valorização do câmbio real.

Figuras 1 e 2

Efeitos de câmbio real para a curva EE no plano (R, Y)

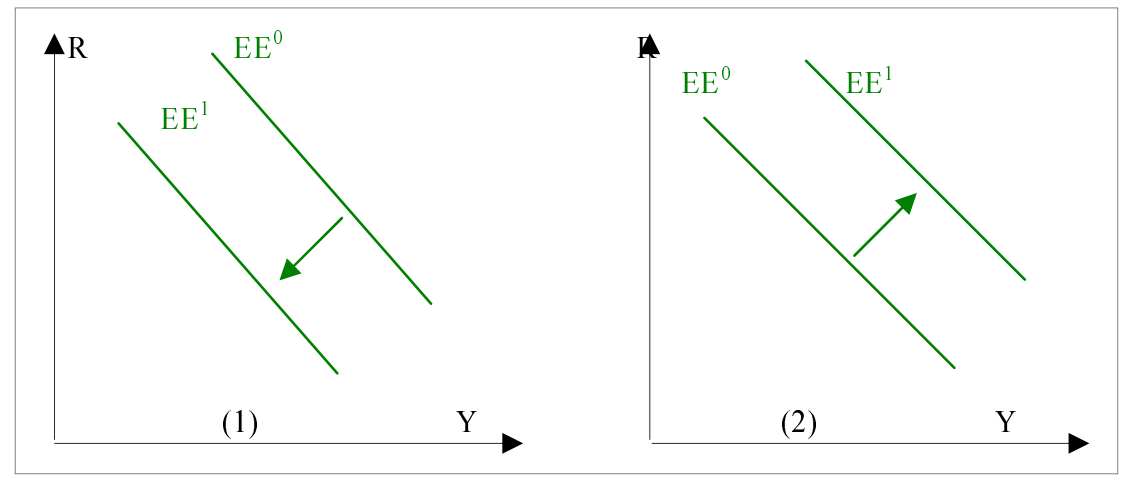

(10) Regulamentos ambientais fracos, portanto bem flexíveis acabam por gerar uma tendência de que as exportações aumentem o grau de poluição e a produção de dejetos em quantidade bem maior do que sob condições de cumprimento de normas e regulamentações fortes (Porter, 1991; Porter; Linde, 1995a; 1995b). 
São movimentos opostos àqueles observados em relação à curva IS, quando de uma desvalorização cambial, o que tenderia a anular a expansão desse movimento em direção ao produto ocorrido pelo deslocamento da IS. Na realidade, a soma dos efeitos do deslocamento positivo (negativo) da IS e do deslocamento negativo (positivo) da EE é o determinante para se saber se ocorreria expansão ou retração do produto no novo equilíbrio. De acordo com Lawn (2003), o efeito dos movimentos cambiais sobre a curva EE estaria condicionado ao modo como os agentes econômicos absorvessem o impacto ambiental. Também, em função de como esses agentes introduzissem processos mais eficientes e limpos na produção, poderia (ou não) haver um deslocamento positivo da curva EE. Torna-se importante salientar que a curva EE reflete os processos produtivos da economia como um agregado, ou seja, ela resulta da ponderação de todo o produto gerado pela economia.

O mesmo ocorre ao haver a ampliação do estoque monetário. Nesse caso, o deslocamento da curva LM, quando a taxa de juros retorna ao nível mundial e a renda alcança um patamar mais elevado, tem efeitos diferentes da tradicional metodologia IS-LM. A restrição ambiental, entretanto, limitaria esse efeito. A análise na economia aberta mantém o balanço de pagamentos em equilíbrio com a taxa de juros interna obedecendo à condição de paridade de taxa de juros coberta.

Formalmente, a incorporação da curva EE, no sistema, ocorre a partir da equação (3), na sequência, em paralelo à inclusão das variáveis: câmbio real, exportações líquidas e renda externa como fatores que influenciam o equilíbrio ambiental.

$$
\left(\frac{-\mathrm{dN}}{\mathrm{dt}}\right)=\left(\frac{\mathrm{Y}}{\mathrm{E}\left(\mathrm{R}, \beta, \gamma, \mathrm{Y}^{*}, \varepsilon, \mathrm{NX}\right)}\right)-\mathrm{s} \cdot \mathrm{N}=0
$$

em que as novas variáveis são $\mathrm{Y}^{*}$, a renda externa, $\mathrm{NX}$, as exportações líquidas e $\varepsilon$, o câmbio real. Note que a equação (3) é equivalente à equação (2), diferenciando-se, contudo, pela presença das variáveis citadas, que são úteis para assinalar a economia aberta.

$\mathrm{Y}^{*}$ corresponde à renda externa e $\varepsilon$ corresponde à taxa de câmbio real, mas, quando

$$
\begin{gathered}
\left(\frac{d N}{d t}\right)=0 \text {, essa condição conduz a: } \\
\left(\frac{\partial \varepsilon}{\partial y}\right)=\left(\frac{E}{Y . E \varepsilon}\right)<0
\end{gathered}
$$

em que $\mathrm{E} \varepsilon$ representa o efeito do câmbio real sobre a curva EE. 
Da equação (4), pode-se ver que, no plano (Y, $\varepsilon$ ), a curva EE tem inclinação negativa. Já, a curva IS, sabe-se que tem inclinação positiva, uma vez que:

$$
\left(\frac{\partial y}{\partial \varepsilon}\right)=\left[\frac{\mathrm{NX} \varepsilon}{(1-\mathrm{Ey}-\mathrm{NXy})}\right]>0
$$

em que NXE representa o efeito do câmbio real sobre as exportações líquidas, Ey representa a sensibilidade da renda sobre a curva IS e, finalmente, $\mathrm{NXy}$, a sensibilidade das exportações líquidas sobre a renda.

A curva LM é vertical no plano $(\mathrm{Y}, \varepsilon)$, dado que:

$$
\left(\frac{\mathrm{M}}{\mathrm{P}}\right)=\mathrm{L}(\mathrm{R}, \mathrm{Y})>0 \quad(6)
$$

em que $\mathrm{M}$ representa o estoque nominal de moeda e $\mathrm{P}$, o nível de preços.

Assim, há apenas uma variável endógena na curva LM (Romer, 1996). Desse modo, tendo a configuração de cada curva no plano $(\mathrm{Y}, \varepsilon)$, pode-se imaginar a configuração da IS-LM-EE na Figura 3 abaixo.

Figura 3

Curvas IS-LM-EE em um Plano $(\varepsilon, Y)$

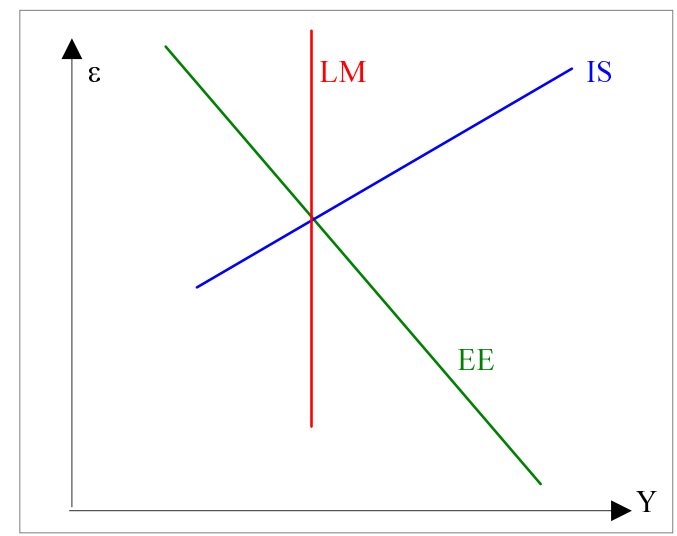

De posse desses resultados, é possível discutir os efeitos da introdução da curva EE em condições de economia aberta, tal como explicitado no diagrama ( $\varepsilon$, Y), o que demonstra a preocupação com os impactos relacionados ao nível do câmbio e do produto. A hipótese, por exemplo, de uma situação na qual o governo de um país adota, em sua política macroeconômica, medidas protecionistas no 
comércio exterior $^{11}$ é perfeitamente factível de ser testada. As medidas deslocam a curva IS para a direita (IS ${ }^{1}$ na Figura 4) e, consequentemente, pode-se observar, em um regime de câmbio flutuante, a valorização do câmbio. Claramente, a restrição ambiental estaria cumprida, quando os lugares geométricos que representam pontos de equilíbrio não fossem ultrapassados. Uma desvalorização da moeda poderia ser feita, contudo, por meio do mercado monetário, ampliando o produto e retornando ao "lócus" de equilíbrio ambiental.

Figura 4

Efeitos de medidas protecionistas no plano $(\varepsilon \cdot, \mathrm{Y})-$ Proposta IS-LM-EE

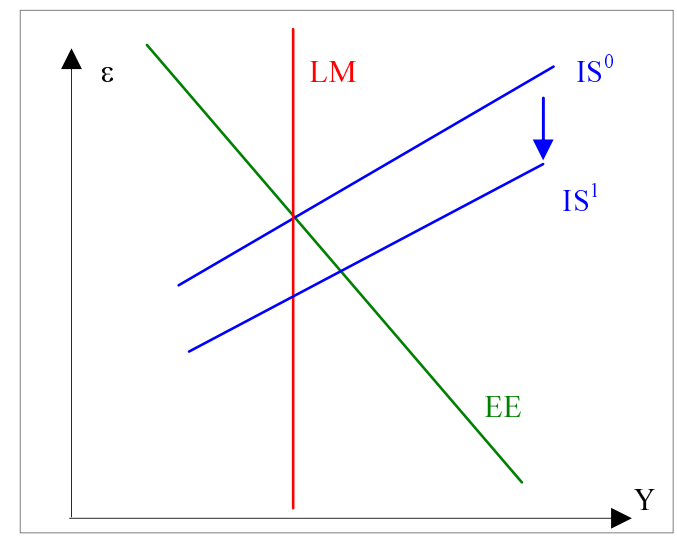

Legenda: 0 representa a posição inicial; 1 , a posição final.

A adoção de tal política pode ser confrontada com uma situação em que o câmbio é fixo (ver Figura 5). Nessa configuração de câmbio, o deslocamento da curva IS, resultante de uma política de medidas protecionistas no comércio externo, seria idêntico. A restrição ambiental, porém, não seria cumprida, pois o novo produto de equilíbrio estaria acima do limite imposto pela sustentabilidade. Do ponto de vista do equilíbrio ambiental, a adoção de medidas protecionistas sob câmbio fixo seria inconsistente. ${ }^{12}$

No caso de um aumento mundial dos juros, com câmbio flutuante na economia doméstica, pode-se verificar que o equilíbrio ambiental alteraria os resultados. Na ausência da curva EE, os deslocamentos da curva IS para a esquerda e o da LM para a direita, no plano $(\varepsilon \cdot$, Y), resultariam em uma taxa de

(11) Caracterizadas por restrições a importações. Assim, não se perceberia o impacto sobre a curva EE.

(12) Coeteris Paribus, na ausência de adoção de técnicas poupadoras de recursos ambientais na economia 
câmbio mais desvalorizada e um nível mais elevado do produto. O movimento da curva LM para a direita teria como função equilibrar o mercado monetário, ajustando a oferta de moeda à queda da demanda real de moeda, consequência do aumento de juros. $^{13}$

Figura 5

Efeitos de Medidas Protecionistas no Plano $(\varepsilon \cdot$, Y) Sob Câmbio Fixo - Proposta IS-LM-EE

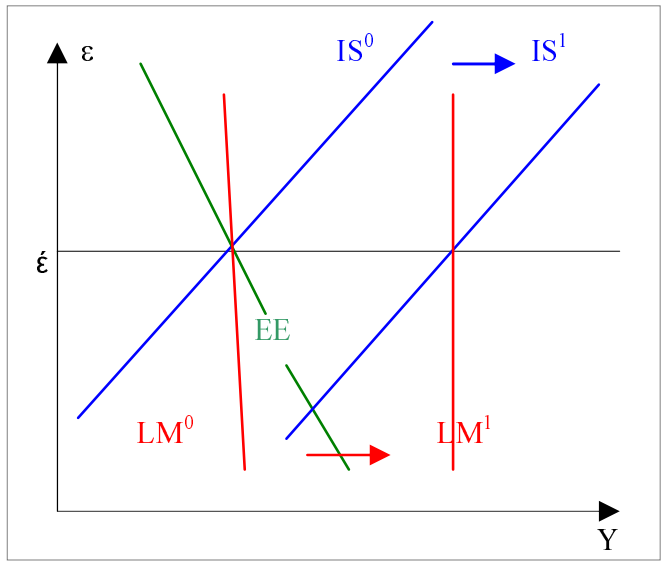

Legenda: $\dot{\varepsilon}$ representa o câmbio fixo; 0 representa a posição inicial; 1, a posição final.

Importante salientar que, na presença da curva EE, seu movimento também seria para a direita devido ao aumento dos juros. Tal movimento abrandaria a restrição ambiental (menor demanda internacional) de modo que um novo equilíbrio, com sustentabilidade, tornar-se-ia viável. Com efeito, o resultado dependeria da sensibilidade relativa da curva $\mathrm{EE}^{14}$ : caso o parâmetro da curva EE ao aumento de juros fosse inferior aos das curvas IS e LM, o equilíbrio ambiental seria restritivo. Consequentemente, o produto final de equilíbrio poderia ser menor e o câmbio estaria mais desvalorizado em relação à situação em que a curva EE inexiste.

Já, em relação ao caso de o câmbio ser fixo, tal como ilustrado na Figura 6, o deslocamento da IS para a esquerda não seria suficiente para constranger o equilíbrio ambiental, uma vez que o produto, em sua posição final, teria um montante inferior ao do equilíbrio inicial em que a sustentabilidade é observada. A

(13) É preciso notar que o pressuposto adotado aqui é o de uma economia pequena, portanto a taxa de juros da economia ajusta-se ao movimento mundial.

(14) Foi por isso que se optou em não ilustrar os movimentos graficamente

Economia e Sociedade, Campinas, v. 20, n. 1 (41), p. 53-78, abr. 2011. 
curva EE, assim, deslocar-se-ia em razão da queda da renda externa, decorrente do aumento de juros.

Figura 6

Efeitos de elevação de juros internacional, sob câmbio fixo no plano $(\varepsilon, Y)$ Proposta IS-LM-EE

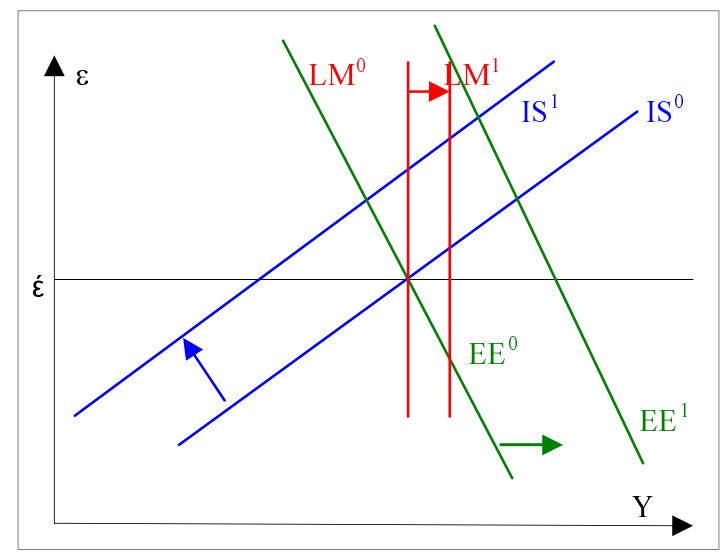

Legenda: ć representa o câmbio fixo;

0 representa a posição inicial; 1 , a posição final.

Uma desvalorização cambial realizada pela autoridade macroeconômica sob o regime de câmbio fixo geraria impactos sobre as curva IS e EE. Tais impactos, entretanto, seriam opostos: a IS tenderia a deslocar o produto para a direita, ao passo que a EE indicaria um deslocamento do produto para a esquerda, comprometendo a sustentabilidade como indicado na Figura 7. Em relação ao plano ( $r, Y$ ), em que ocorreriam deslocamentos da curva EE e da IS, respectivamente para a esquerda e para a direita, também se perceberia uma taxa de juros maior do que aquela verificada na situação inicial de equilíbrio antes da desvalorização. ${ }^{15}$

Finalmente, como última ilustração, para o caso de controle de capitais assumir-se-á que o balanço de pagamentos será mantido em equilíbrio, ou seja, a deterioração do fluxo de capitais corresponderá a uma melhora da balança comercial e vice-versa. O primeiro fato a ser notado é que, sob tal regime, poderá regular-se a destinação do ingresso de capital, permitindo, assim, a uma autoridade monetária hipotética que avalie a sustentabilidade ambiental. Dessa forma, restringirá os setores (intensivos em capital natural ou não) que recepcionarão o investimento direto, deslocando o equilíbrio ambiental. Caso a opção seja não discriminar a destinação, mas realizar o controle independente de seu objetivo, assume-se a mobilidade imperfeita de capitais baseada no diferencial de juros

(15) Nesse caso, a LM deslocar-se-ia à esquerda, equilibrando o mercado. 
praticado na economia nacional e no mercado mundial de ativos, combinado a um regime de câmbio flutuante.

Figura 7

Efeitos de Mudança (Desvalorização) de Câmbio Fixo $(\varepsilon \cdot$, Y)

- Proposta IS-LM-EE

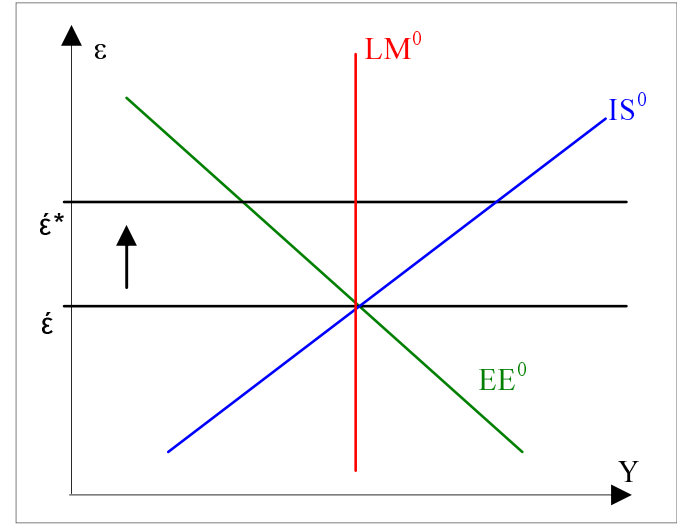

Legenda: $\dot{\varepsilon}$ representa o câmbio fixo; 0 representa a posição inicial; 1, a posição final.

Desse modo, um aumento nos juros do mercado internacional (ou maior controle de capitais na economia nacional) provocaria menor ingresso de capitais, reduzindo o saldo de capital na economia nacional a ser compensado por um aumento das exportações líquidas ou saldo comercial. Como consequência, a curva EE deslocar-se-ia no sentido de ampliar a restrição ambiental, já que as exportações líquidas fazem parte de sua determinação (equação (3)). De outra forma, um aumento na taxa de juros nacional (ou relaxamento dos controles de capitais) acarretaria na entrada de recursos via conta de capital e provocaria, para garantir o equilíbrio no balanço de pagamentos, a redução das exportações líquidas. Resultaria, enfim, em um deslocamento do equilíbrio ambiental, garantindo o deslocamento no sentido de abrandar o equilíbrio ambiental. Ressalte-se que, como o equilíbrio ambiental é, também, função do comportamento do câmbio, os efeitos citados serão amplificados com os comportamentos correspondentes ao câmbio, com desvalorização no primeiro caso e valorização no segundo caso.

Um aspecto importante aqui é o fato de ser plenamente possível uma abordagem que considere o câmbio como variável endógena na determinação da curva LM. A opção, todavia, nesse artigo, por considerá-lo uma variável exógena, tem como principal objetivo ilustrar os distintos efeitos sob diferentes políticas cambiais. 
Essas análises devem levar em conta, como discutiremos na próxima seção, que nos países em desenvolvimento, a curva EE é mais sensível em relação aos fatores de comércio internacional do que nos países desenvolvidos. Ao se reconhecer o equilíbrio ambiental, os impactos do comércio internacional nesses últimos são, de fato, mais suscetíveis ao comportamento da política macroeconômica, já que a curva EE seria menos sensível. Os países em desenvolvimento, por sua vez, estariam mais dependentes da sensibilidade apresentada pela curva EE. Assim, a configuração dessa curva adquire importância central na determinação de políticas de inserção internacional dentro de um contexto de política econômica que visa ao crescimento do produto, mantendo-se o nível do estoque natural.

Em suma, somente a contextualização da economia superaria os limites impostos pela análise teórica. Reforçando tal ponto de vista, Heyes (2000) e Lawn (2003) incorporaram, na formulação do modelo IS-LM-EE, aspectos institucionais que deslocariam o conjunto de pontos que formam a curva EE. O primeiro autor destacou a possibilidade de um planejador público deslocar a curva rumo a um nível sustentável por meio de políticas que fortaleceriam o "enforcement" relativo a leis e costumes ambientais ou mesmo políticas que direcionariam as instituições para o princípio do poluidor-pagador. Tais medidas deslocariam a curva EE para a direita e, de acordo com Heyes, criariam condições para uma expansão da renda de modo sustentável.

\section{O padrão ambiental do comércio internacional}

O esquema teórico apresentado e discutido na seção anterior limita-se às observações metodológicas gerais. Suas aplicações, principalmente, os resultados estão restritos ao exame da realidade particular dos casos analisados, cabendo ao analista a sensibilidade de bem particularizá-lo. Em especial, o modelo discutido neste artigo deve ser caracterizado em função da inserção das economias nacionais no comércio internacional e discutido à luz da disponibilidade de recursos naturais e da divisão internacional do trabalho. O objetivo desta seção é, portanto, verificar os diferentes impactos gerados pelo padrão ambiental do comércio internacional em relação aos países em desenvolvimento e, ao mesmo tempo, notar as limitações da teoria.

O comércio internacional caracteriza-se por uma predominância da denominada tríade (Japão, Europa e Estados Unidos) na contratação de volumes de mercadorias e geração de tecnologia, além da concentração de investimento direto estrangeiro (Dicken, 1998; Hoekman; Kostecki, 2001). Tal domínio tem sofrido nas últimas décadas, de alguma maneira, resistências em vista do avanço dos países chamados de "tigres asiáticos" e da China. A tríade, contudo, ainda 
predomina de forma expressiva no volume e no poder político expresso em organismos como a Organização Mundial do Comércio (OMC).

Hoekman e Kostecki (2001) destacam a globalização como um fenômeno crescente, caracterizando o comércio intraindustrial que desloca as plantas industriais pelo mundo, à procura de vantagens na obtenção de fatores de produção, notadamente, mão de obra. A intensidade das exportações, porém, fica predominantemente concentrada nos recursos naturais, apesar da tendência declinante, conforme ilustrado pela Tabela 2.

Tabela 2

Fator de intensidade das exportações, 1988 e 1998

\begin{tabular}{l|r|r|r|r|r|r|r|r}
\hline & \multicolumn{2}{|c|}{$\begin{array}{c}\text { Recursos } \\
\text { Naturais }\end{array}$} & \multicolumn{2}{c|}{ Trabalho } & \multicolumn{2}{c|}{ Tecnologia } & \multicolumn{2}{c}{$\begin{array}{c}\text { Capital } \\
\text { Humano }\end{array}$} \\
\hline & 1988 & 1998 & 1988 & 1998 & 1988 & 1998 & 1988 & 1998 \\
\hline Países Desenvolvidos & 22.5 & 17.9 & 9.8 & 9.7 & 39.4 & 45.2 & 28.3 & 37.1 \\
\hline Países em Desenvolvimento & 27.2 & 16.8 & 30.5 & 24.0 & 23.8 & 42.6 & 18.5 & 16.6 \\
\hline Leste Ásia & 50.2 & 15.9 & 35.9 & 81.2 & 7.9 & 2.2 & 6.1 & 0.6 \\
\hline Sul da Ásia & 67.0 & 42.4 & 5.8 & 9.3 & 13.4 & 25.4 & 13.8 & 22.9 \\
\hline América Latina & 78.3 & 79.0 & 6.0 & 5.9 & 6.6 & 7.7 & 9.1 & 7.4 \\
\hline África Sub Saahariana & 38.0 & 37.6 & 23.9 & 18.4 & 20.2 & 21.3 & 17.8 & 22.7 \\
\hline Ásia Central e Leste Europeu & 80.3 & 65.6 & 3.7 & 8.0 & 13.1 & 22.0 & 2.9 & 4.3 \\
\hline Oriente Médio e África do Norte & \multicolumn{1}{|c|}{} & & & & & & \\
\hline
\end{tabular}

Fonte: Hoekman e Kostecki (2001, p. 14).

Já, Young e Lustosa (2003) partiram de uma análise baseada na relação centro-periferia, com clara influência cepalina, para demonstrar de que maneira a periferia econômica (os países em desenvolvimento) sofre mais intensamente os efeitos ambientais. Ao imitarem os padrões tecnológicos a partir do centro, os países periféricos sujeitam-se à mesma sorte de problemas dos países centrais, sem, contudo, atingirem um patamar de desenvolvimento socioeconômico compatível. A queima de combustíveis fósseis e o consumo energético perdulário são exemplos de problemas ambientais acelerados nos países em desenvolvimento, sendo que tal problema não se resume apenas à produção, mas também à reprodução de padrões de consumo igualmente perdulários. Os autores citados apontam, além disso, a expansão populacional como um fator de pressão para a expansão das fronteiras agrícolas, sendo as áreas naturais de floresta o custo desse processo.

A expansão de fronteira agrícola não se dá somente por conta da expansão populacional (boa parte dos países em desenvolvimento ainda se encontra na fase de transição demográfica), mas também pelo aumento dos mercados exportadores dos países em desenvolvimento. O exemplo recente do Brasil com a cultura de soja, que se expandiu nas últimas duas décadas a ponto de assumir a liderança 
mundial de produção é emblemático do problema de expansão de fronteira agrícola ao custo de áreas de floresta natural. Outro aspecto de fundamental importância é o fato de a pressão dos produtores ter maior peso político, determinando uma política ambiental favorável a seu negócio. ${ }^{16}$ Por outro lado, Brandão, Rezende e Marques (2005) não associam a expansão de lavouras de soja como causa direta da perda de recursos naturais na Amazônia brasileira. As lavouras, que se destinam predominantemente ao mercado mundial, seriam constituídas em antigas pastagens, sendo outros fatores, notadamente os institucionais, mais importantes do que a expansão da lavoura de soja que teve, no período de livre flutuação cambial, iniciado em 1999, preços favoráveis no mercado internacional.

Torna-se necessário salientar que a estratégia de desenvolvimento dos países em desenvolvimento é, em geral, orientada para explorar a vantagem comparativa da abundância de recursos naturais. Young (1998) utilizou o Brasil como exemplo dessa estratégia no contexto de uma política de promoção das exportações fazendo resultar um aumento das poluições atmosférica e hídrica. $\mathrm{Na}$ análise da matriz de insumo-produto proposta pelo referido autor para o período de 1980 a 1985, pode-se verificar que as indústrias voltadas à exportação são mais poluidoras, sobretudo pelos coeficientes de intensidade, do que a média dos demais setores da economia. Segundo o próprio Young, dois elementos são decisivos para explicar o resultado obtido: a maturação dos investimentos relacionados ao II PND e os incentivos criados no início dos anos 80 para as indústrias exportadoras.

Em idêntica linha de argumentação, Paula et al. (1997) argumentaram que os países centrais buscam o desenvolvimento de produtos com tecnologias inovadoras, substituindo os produtos anteriores. O papel dos países "ávidos por crescimento", na terminologia dos autores, internaliza as indústrias poluidoras e geradoras de depreciações ambientais.

Nessa mesma linha de argumentação, embora voltada à questão das reformas macroeconômicas que propiciam a mitigação dos impactos ambientais gerados pelo crescimento econômico, Munasinghe (2004) demonstra que o timing das políticas pode ser um importante fator. Um movimento, coeteris paribus, no sentido da desvalorização e/ou abertura comercial, conquista o investimento estrangeiro e a expansão das indústrias intensivas de energia, atraídas, em parte, pelo baixo preço do fator. Assim, ao mesmo tempo, reconhece o potencial de menor bem-estar ambiental frente a uma abertura comercial ou desvalorização,

(16) Os principais estados onde a situação ocorre são: Mato Grosso, Pará e Rondônia. A liberação do plantio das sementes transgênicas serve como exemplo do poder do agronegócio em ditar os regulamentos institucionais, conforme adquirem importância comercial. 
ilustra a necessidade de se perseguir políticas macroeconômicas "win-win", havendo, portanto, ganhos para todos os envolvidos.

O resultado obtido para o Brasil pode constituir-se em uma generalização para a maioria dos países em desenvolvimento com indústrias relativamente representativas. Em paralelo, pode-se perceber que os regulamentos relativos às preocupações ambientais são mais frágeis ou, quando não, de dificultosa implementação nesses países. Ainda que sejam considerados os que não possuem setor industrial exportador representativo, o universo de tais países será o daqueles que exportam matérias-primas, minerais e vegetais para a industrialização em outros parques industriais. Assim, mesmo no caso de países com atividades predominantemente primárias, a degradação ambiental está presente na forma de resíduos das atividades de mineração ou esgotamento dos recursos naturais. ${ }^{17}$ Coxhead e Shively (1995), por exemplo, apontaram impactos sobre a degradação da terra do comércio internacional nas Filipinas. O custo associado, sob determinadas hipóteses, chegou a alcançar $4 \%$ dos gastos totais do governo com a agricultura. Já, Goldin e Host's (1997) mostraram a existência de maiores dificuldades no fornecimento de água no Marrocos frente a uma liberalização comercial unilateral.

Além disso, com a hipótese de que os países tenham alcançado níveis diferenciados de desenvolvimento econômico, os níveis de degradação ambiental estão propensos a ter retornos marginais menores e até mesmo negativos a partir de um determinado ponto. Essa hipótese foi formulada por Grossman e Krueger (1993) a partir da avaliação dos impactos ambientais no México gerados com a criação do NAFTA, sendo a parte teórica concebida posteriormente (1995) e conhecida na literatura por Curva Ambiental de Kuznets. No que diz respeito ao comércio internacional, a Curva Ambiental de Kuznets baseia-se na suposição de que o crescimento econômico acaba por propiciar escolhas tecnológicas limpas (Bousquet; Favard, 2000). As evidências a respeito da existência da Curva Ambiental de Kuznets são inconclusas, mas pode-se perceber que ela está relacionada sensivelmente à maneira como se desenvolve a economia.

Dasgupta et al. (2002) listam vários fatores que podem se comportar de maneira diferente: regulação ambiental, liberalização econômica, regulação informal, pressão dos agentes de mercado e métodos mais eficientes de informação. Tais autores (2002, p. 163) salientam que:

(17) Nesse aspecto, o caso dos países africanos é emblemático, uma vez que a quase extinção de elefantes, cujo produto é o marfim e as consequências ambientais e sociopolíticas da exploração de minérios na República Democrática do Congo são exemplos concretos. O mesmo vale aos países exportadores de petróleo, membros da Opep. 
The evidence on how regulatory capability can be developed is sparse, but the World Bank's indicators of institutional and policy development provide grounds for moderate optimism.

Esses mesmos autores além de Torras e Boyce (1998) associam o comportamento da Curva Ambiental de Kuznets com a desigualdade de renda e oportunidades, relacionando urbanização, analfabetismo, liberdades civis e direitos políticos como fatores importantes para determinar a verificação da hipótese.

Mais interessante pela abordagem é o trabalho de Suri e Chapman (1998) que procuraram verificar a existência da Curva Ambiental de Kuznets em um contexto de comércio internacional, tendo como critério de deterioração ambiental o consumo energético. Os resultados obtidos pelos dois autores, considerando-se o comércio internacional, não são favoráveis à viabilidade prática ${ }^{18}$ da hipótese da Curva Ambiental de Kuznets. O impacto é mais importante nos países em desenvolvimento:

In rapidly industrializing countries, which lie on the steep segment of the upward sloping part of the curve, exports of manufactured goods have been a key source driving their energy consumption. This rapid increase in energy, combined with negligible controls on pollutant has resulted in rapid increases in pollutant emissions. Most exports from industrializing countries are consumed in industrialized countries (Suri; Chapman, 1998, p. 205).

Henderson (1991) e Nobre e Amazonas (2002) recordam que o debate acerca de uma presumível sustentabilidade ambiental, acontece, essencialmente, entre os países do Norte, desenvolvidos de um lado e os países do Sul, em desenvolvimento, do outro. Os países do Norte mantêm padrões de consumo baseados na exploração de recursos naturais obtidos por meio do comércio internacional junto aos países do Sul e mesmo esses padrões são perdulários no consumo de energia e materiais, necessitando, conforme Daly (1989), do estabelecimento de limites de consumo e renda, além de garantir renda mínima aos pobres. Como ainda lembra Henderson (1991), os países do Sul precisam de mecanismos capazes de financiar seu desenvolvimento sustentável. Para tal, necessitam de indicadores, medidas mais adequadas, ao mesmo tempo, maior multilateralismo nas negociações dos acordos internacionais, pois “do contrário, o poder dos países industrializados do Norte - com sua participação mais ampla e melhor financiados - acabaria por dominar as discussões em todos os encontros e conferências mundiais" (Henderson, 1991, p. 205).

É válido notar que o padrão poluente do comércio internacional nos países em desenvolvimento não é, necessariamente, generalizado. Observando o exemplo

(18) Embora tenham sido favoráveis à viabilidade teórica, os pesquisadores encontraram níveis de renda per capita como US\$ 55 mil e US\$ 224 mil para que ocorresse a inversão para rendimentos marginais negativos no nível de poluição. Nenhuma economia encontra-se próxima desse nível no momento. 
da Costa Rica, estímulos ao comércio internacional resultam em atividades sustentáveis como o fluxo de turistas para observação e desfrute das riquezas naturais do país. Esse comprometimento da Costa Rica com o desenvolvimento sustentável aproxima-a dos países desenvolvidos no que diz respeito aos impactos do estímulo do comércio internacional. Nos países desenvolvidos, contrário aos países em desenvolvimento, estímulos do comércio internacional resultam em atividades sustentáveis, já que há regulamentação forte e adequada, além de outro padrão de inserção, internacional, dos produtos. As plantas industriais poluentes e de exploração dos recursos naturais estão concentradas, como vimos, nos países em desenvolvimento, notadamente, América Latina, Oriente Médio e África.

\section{Considerações finais}

Embora a metodologia IS-LM-EE, proposta por Heyes (2000), represente uma evolução em relação às tradicionais análises de modelos macroeconômicos, incorporando a restrição ambiental, ainda possui limitações evidentes. O objetivo central deste artigo é superar uma das limitações, ampliando o modelo para um contexto de economia aberta. Após a apresentação do modelo em que o equilíbrio ambiental é incorporado, introduziram-se, na definição da posição do equilíbrio ambiental (trajetória de sustentabilidade), fatores de uma economia aberta como o nível de renda externo, as exportações líquidas (fluxo de comércio) e a taxa de câmbio. Aperfeiçoamentos futuros poderão ser concentrados no comportamento da taxa de câmbio frente às variáveis do modelo, especialmente, em como ela seria determinada na nova configuração. Outra linha de pesquisa futura deverá concentrar-se na determinação efetiva de critérios para a estimação de curvas EE no nível das economias nacionais.

Demonstrou-se o resultado sobre a economia de alguns efeitos decorrentes da política econômica sobre a posição de equilíbrio ambiental. Como ilustração, os seguintes casos foram examinados: regime de câmbio flutuante e fixo, aumento de juro internacional e alterações em políticas comerciais. Também, foram analisadas as ocorrências de desvalorização sob regime de câmbio fixo e efeitos sob regime de mobilidade imperfeita de capitais (controle de capitais). A partir da definição da curva de equilíbrio ambiental (EE) e das definições das curvas IS e LM, é plenamente possível examinar-se os efeitos de qualquer alteração da política econômica.

É necessário, no entanto, observar, independentemente da definição teórica, que a curva de equilíbrio ambiental (EE) tal como seus pares IS e LM possui particularidades para as economias nacionais. A disparidade com reações de adoções de políticas e respostas aos choques é ampliada no caso da incorporação das restrições ambientais, sobretudo quando se consideram os choques exógenos derivados do comércio internacional. De fato, os países em 
desenvolvimento estão mais expostos aos impactos ambientais derivados de estímulos ao comércio internacional, já que fazem valer sua vantagem comparativa de possuir, ainda, recursos naturais em abundância relativa, o que se confirma pelo perfil de suas exportações. Ademais, pode-se apontar o fator institucional como de fundamental importância na medida em que, nos países em desenvolvimento, predominam regulamentos ambientais mais brandos, o que acaba por gerar uma tendência de que as exportações aumentem o grau de poluição e produção de dejetos, impactando, diretamente, o coeficiente de throughtput de energia material.

Como há, na presente conjuntura internacional, uma nítida preocupação com a trajetória de sustentabilidade dos recursos naturais ainda disponíveis, associada a uma necessidade de desenvolvimento econômico dos países em desenvolvimento, torna-se necessário serem avaliadas metodologias que apontem a conciliação dos interesses socioeconômicos e ambientais. Questões como a eficiência na utilização de recursos que incremente a tecnologia existente e gere maior produtividade agrícola poderá beneficiar o alcance deste fim. Tais questões estão presentes na definição da curva de equilíbrio ambiental e poderão, portanto, ser úteis na definição de uma política econômica que contemple o desenvolvimento sustentável.

\section{Referências bibliográficas}

ALLEN, C. S. The underdevelopment of Keynesianism in the federal republic of Germany. In: HALL, P. A. (Ed.). The political power of economic ideas: Keynesianism across nations. Princeton, New Jersey: Princeton University Press, 1989. p. 263-289.

ANDRADE, A. A. S.; MAGALHÃES, M. A. IS-LM: uma história? Revista de Economia Politica, v. 24, n. 4, p. 523-542, 2004.

ATKINSON, G.; DUBOURG, R.; HAMILTON, K. Measuring sustainable development: macroeconomics and the environment. Cheltenham, UK: Edward Elgar, 1997.

AYRES, R. U. Resources, environment and economics. London: John Wiley \& Sons, 1978.

. Eco-thermodynamics: economics and the second law. Ecological Economics, v. 26 , p. $189-209,1998$.

BHAGWATI, J. Em defesa da globalização: como a globalização está ajudando ricos e pobres. Rio de Janeiro: Elsevier, 2004.

BOUSQUET, A.; FAVARD, P. Does S. Kuznets' belief question the environmental Kuznets curve? Université des Sciences Sociales Toulouse, 2000. Mimeografado.

BRANDÃO, A. S. P.; REZENDE, G. C.; MARQUES, R. V. C. Crescimento agrícola no Brasil no período 1999-2004: explosão da soja e da pecuária bovina e seu impacto sobre o meio ambiente. Rio de Janeiro: IPEA, 2005. (Texto para Discussão, n. 1.103). 
CMMAD - Comissão Mundial sobre Meio Ambiente e Desenvolvimento. Nosso futuro comum. Rio de Janeiro: Editora da Fundação Getúlio Vargas, 1991.

COXHEAD, I.; SHIVELY, G. Measuring the environmental impacts of economic change: the case of land degradation in Phillipine agriculture. University of Wiscosin-Madison. Department of Agricultural Economics, 1995. (Staff Paper Series, n. 384).

DALY, H. Toward the common good. Boston: Beacon Press, 1989.

Towards an environmental macroeconomics. Land Economics, v. 67, p. 255$259,1991$.

DASGUPTA, S.; LAPlante, B.; WANG, H.; WHEELER, D. Confronting the environmental Kuznets curve. Journal of Economic Perspectives, v. 16, p. 147-168, 2002.

DICKEN, P. The global economic map: trends in production, trade and investment. In: DICKENS, P. (Org.). Global shift: transforming the world economy. New York: Guilford, 1998. p. 24-70.

EL SERAFY, S. Contabilidade verde e política econômica. In: CAVALCANTI, C. (Org.). Meio ambiente, desenvolvimento sustentável e políticas públicas. São Paulo: Cortez; Recife: Fundação Joaquim Nabuco, 1999. p. 193-214.

FIORI, J. L. Os moedeiros falsos. Petrópolis, RJ: Vozes, 1997.

FLEMING, J. M. Domestic financial policies under fixed and under floating exchange rates. IMF Staff Papers, 1962.

FULLERTON, D.; STEVENS, R. How economists see the environment. Nature, v. 395, p. 433-434, 1998.

GOLDIN, I.; HOST, D. R. Economic policies for sustainable resource use in Morocco. In: CRUZ, W.; MUNASINGHE, M.; WARFORD, J. (Org.). The greening of economic policy reform. Washington, DC: World Bank, 1997. v. II: case studies, chapt. 3.

GROSSMAN, M.; KRUEGER, A. Environmental impacts of the North American free trade agreement. In: GARBER, P. (Org.). The US-Mexico free trade agreement. Cambridge: MIT Press, 1993. p. 13-56.

Economics, v. 110, p. 353-377, 1995.

HALL, P. A. (Org.). The political power of economic ideas: Keynesianism across nations. Princeton, New Jersey: Princeton University Press, 1989.

HARRIS, J. Macroeconomic policy and sustainability. Global Development and Environment Institute, 2001. (Working Paper, n. 01-09).

HEUSEMANN, M. H. The limits of technological solutions to sustainable development. Clean Tech Environment Policy, v. 5, p. 31-24, 2003.

HENDERSON, H. Transcendendo a economia. São Paulo: Cultrix, 1991.

HEYES, A. A proposal for the greening of the textbook macro: IS-LM-EE. Ecological Economics, v. 32, p. 1-7, 2000. 
HICKS, J. Mr. Keynes and the classics: a suggested interpretation. Econometrica, v. 5, n. 1, p. 147-159, 1937.

HIRSCHMAN, A.O. How the Keynesian revolution was exported from the United States, and other comments. In: HALL, P. A. (Org.). The political power of economic ideas: Keynesianism across nations. Princeton, New Jersey: Princeton University Press, 1989. p. 347-359.

HOEKMAN, B.; KOSTECKI, M. The political economy of the world trading system: WTO and beyond. London: Oxford University Press, 2001.

JOGERSON, D. W.; CHRISTENSEN, L. R.; LAU, L. J. Transcendental logarithmic production frontiers. Review of Economic and Statistics, v. 55, n. 1, p. 28-45, 1973.

KEYNES, J. M. Teoria geral do emprego, do juro e da moeda. São Paulo: Nova Cultural, 1985.

KRUGMAN, P. R.; OBSTFELD, M. Economia internacional: teoria e política. São Paulo: Makron Books, 1999.

KRUGMAN, P. R. There's something about macro. 1998. Disponível em: http://web.mit.edu/krugman/www/islm.html.

LAWN, P. A. On Heyes's IS-LM-EE proposal to establish an environmental macroeconomics. Environment and Development Economics, v. 8, p. 31-56, 2003.

LEONTIEF, W. Environmental repercussions and the economic structure: an input-output approach. Review of Economic Statistics, v. 52, p. 262-277, 1970.

MUELLER, C. C. Economia do meio ambiente na perspectiva do mundo industrializado: uma avaliação da economia ambiental neoclássica. Estudos Econômicos, v. 26, p. 261304, 1997.

Economia, entropia e sustentabilidade: abordagem e visões do futuro da economia da sobrevivência. Estudos Econômicos, v. 29, p. 513-550, 1999.

MUNASINGHE, $M$. Is environmental degradation an inevitable consequence of economic growth: tunneling through the environmental Kuznets curve. Ecological Economics, v. 29, p. 89-109, 1999.

. Environmental macroeconomics - Basic principles. Munasinghe Institute for

Development (MIND), Colombo, Sri Lanka, 2004. Disponível em: http://research.yale.edu/cbey/uploads/File/Munasinghe 4.pdf.

MUNDELL, R. International economics. New York: McMillan, 1968.

NOBRE, M.; AMAZONAS, M. C. (Org.). Desenvolvimento sustentóvel: a institucionalização de um conceito. Brasília: Ibama, 2002.

OLIKKAINEN, M. Sustainable development from the viewpoints of ethics and economics. In: TYLECOTE, A.; VAN DER STRAATEN, J. (Org.). Environment, technology and economic growth: the challenge to sustainable development. Cheltenham, UK: Edward Elgar, 1997. p. 39-54.

PAUlA, J. A.; GUERRA, C.; BRITO, F. R. A.; BARBOSA, F.; NABUCO, M. R. Dinâmica capitalista, divisão internacional do trabalho e meio ambiente. In: PAULA, João 
Antônio de (Org.). Biodiversidade, população e economia: uma região de Mata Atlântica. Belo Horizonte: UFMG/Cedeplar; ECMVC; PADCT/CIAMB, 1997. p. 27-46.

PEARCE, D.; WARFORD, J. World without end: Economics, Environment and Sustainable Development. New York: Oxford University Press, 1993.

PORTER, M.; VAN DER LINDE, C. Toward a new conception of the environmentcompetitiveness relationship. Journal of Economic Perspectives, v. 9, n. 4, p. 97-118, 1995.

; . Green and competitive: ending the stalemate. Harvard Business Review, v. 73, n. 5, p. 120-134, 1995.

. America's green strategy. Scientific American, v. 264, p. 168, 1991.

RICKER, M. Limits to economic growth as shown by a computable general equilibrium model. Ecological Economics, v. 21, p. 141-158, 1997.

ROMER, D. Advanced macroeconomics. New York: The McGraw-Hill, 1996.

SACHS, J. D.; LARRAIN, B. F. Macroeconomia. São Paulo: Makron Books, 1998.

SURI, V.; CHAPMAN, D. Economic growth, trade and energy: implications for the environmental Kuznets curve. Ecological Economics, v. 25, p. 195-208, 1998.

TORRAS, M.; BOYCE, J. K. Income, inequality and pollution: a reassessment of the environmental Kuznets curve. Ecological Economics, v. 25, p. 147-160, 1998.

YOUNG, C. E. F. Industrial pollution and export-oriented policies in Brazil. Revista Brasileira de Economia, v. 52, n. 4, p. 543-561, 1998.

; LUSTOSA, M. C. J. A questão ambiental no esquema centro-periferia. Economia, v. 4, n. 2, p. 201-221, 2003. 